\title{
Responses of Nigerian Universities to the use of Technology-Based Teaching Strategies: Students' Perspective from Cross River University of Technology, Cross River State, Nigeria
}

\author{
Idaka Idaka, PhD \\ Akubuiro, I. M., PhD \\ Department of Eductional Foundations, Guidance and Counseling \\ University of Calabar.
}

\section{Doi:10.5901/jesr.2013.v4n3p143}

\section{Abstract}

As we move into a technology-based society, the use of technology-based teaching strategies in the training of tomorrow's workforce has become inevitable. The purpose of this study is to examine undergraduates' level of exposure to technologybased teaching strategies, and to further determine if such level is a function of their area and year of study. A sample of 624 students was randomly selected from Cross River University of Technology students. A questionnaire was the instrument for data collection and three null hypotheses were tested at .05 level of significance. The results indicated that students sampled revealed that their level of exposure to technology-based teaching strategies was significantly low. Based on this, certain recommendations were made.

Keywords: Technology-based teaching strategies, Cross River University of Technology, ANOVA.

\section{Introduction}

In recent years, advances in technology and in particular computer-related technologies have opened the doors of opportunities for curricular changes on both the methods and materials for instruction. The approaches used for teaching have changed in the past two decades with an increased focus on understanding concepts, using active learning strategies and using real-world data. Accordingly, in most countries of the world, more teachers are integrating technology into their instruction.

Technology-based Teaching Strategies (TTS) take advantage of the unique properties of educational technology to help students master material and skills. The technology involved, varies depending on the teacher's instructional goals, the students' level and instructional needs, and available resources.

Of course, technology-based teaching strategies offer several advantages over more traditional methods of presenting materials. Technology allows students to work on problems that would be difficult or impossible otherwise. For e.g, a genetic simulation programme allows students to specify an organism's genotype, systematically test hypotheses about genetic principles and see the results of many generation of virtual offspring with a single laboratory class (Sterwart, Hafner, Johnson \& Finkel, 1992); allows students to learn how to diagnose and repair problems in sophisticated equipments learning about expensive and dangerous equipment without harming themselves or the equipment (Lesgold, Lajoie, Buwzo \& Eggan, 1992); CD-ROMs and laser video discs allow students not only read and hear about processes and changes but also see the dynamics of such changes. Unlike slides and videotapes, students can precisely control how quickly the changes progress so that they can carefully examine and understand the causes and results. One can imagine the deeper understanding that would be achieved if CD-ROMs and laser video-discs are used in teaching students the life cycle of a butterfly.

Besides, students and teachers can use computer networks to communicate with users across universities or countries. Networks also offer high speed access to resources and expertise that otherwise would not be available, giving up-to-date and accurate information about virtually any topic of interest.

According to Elliot, Kratoch-will, Cook, and Travers (2000), teachers can use technology in many ways in their teaching. These include: -

i. Web-based instruction

ii. Audio virtual aids 
iii. Teaching technology

iv. Intelligent tutoring system

v. Multi-media

vi. Computer-Assisted instruction

Web Based Instruction (WBI): The World Wide Web (WWW) is an organized system of computer networks that allows users to transmit and search information using many different branching pathways. One can therefore, find information quickly, without having to go through too many intervening websites. It allows one to easily browse through many different links among websites which enables a user look up related topics quickly and easily.

WBI uses the information search and transmitting capabilities of the www and the vast array of resources available on it to provide instruction to students (Khan, 1997). Hence, students and teachers can access information and materials, experiences and expertise that would have been very difficult to obtain.

The scope of education for students moves beyond what is locally available and immediately affordable to include 'virtual' world travel, world-class scientific experimentation, expertise, and international exploration. With WBI therefore, there is improvement in the quality of learning as students develop problem-solving, information evaluation and information search skills (Owston, 1997).

Audio-virtual Aids: These involve using technology to present information in several formats (vision, audition) to supplement a teacher-or-text based presentation.

Teaching technology: This involves teaching students the basics of how to use the technology itself, e.g. how to use word-processing, packages, spreadsheets, graphing programmes, etc.

Computer Assisted Instruction (CAI): which involves using technology to present materials to students initially and to assist them in mastering it. Example includes drill and practice softwares.

Intelligent Tutoring System (ITS): This involves using technology to provide an individualized tutor for each student. The system presents new material in a way that is comprehensible to each student; provides examples and practice problems, tracks student performance, identify errors and misconception and provide appropriate guidance and feedback. Example is Sherlock (an avionics tutor).

Multimedia: Involves using technology to integrate and simultaneously use several different types of technology. This is often based on cognitive constructivist theory, and often involves students in collaborative large-scale practice. Examples include Laser videodisc series (Jasper wood bury) and CD-ROMs (National Geographic Society Series).

Virtual Reality (VR): This is a computer generated environment that is three-dimensional and involves the user in real time multi-sensory interactions. According to Walser(1990), the exciting aspect of VR systems for learning is that students will be able to engage in interactive learning that combines cognitive, affective and psychomotor skills. For example, biology and medical students could perform operations on 'virtual' patients to learn about various organ systems and the effects of different treatments, learning activities which are clearly not possible in 'real' reality. This system is presently being used for training and education in areas like physics, chemistry, biology and music (Larijani, 1994).

Of course, the benefits of technology-based teaching strategies (TTS) have been extolled in the literature, it is therefore imperative to conduct a study like this present one in Nigeria, and particularly in a University of Technology as the findings may provide scope and direction.

The purpose of this study is therefore to determine the extent to which students of CRUTECH are exposed to technology based teaching strategies and whether the extent of their exposure is a function of their years and areas of study.

\section{Research Questions}

i. To what extent is CRUTECH students exposed to technology based teaching strategies?

ii. How does year of study affect students' exposure to technology-based teaching strategies?

iii. How does area of study affect students' exposure to technology-based teaching strategies?

\section{Hypotheses}

i. Students' exposure to technology-based teaching strategies is not significantly high.

ii. Year of study does not significantly influence students' exposure to technology-based teaching strategies.

iii. Area of study does not significantly influence students' exposure to technology-based teaching strategies. 


\section{Methodology}

The research design adopted for this study was the descriptive survey. The accessible population for this study was all the students of Cross River University of Technology, main-campus numbering about eight thousand nine hundred $(8,900)$ for the 2009/2010 academic year. The sample of 624 students was selected using proportional stratified and simple random sampling techniques with area of study and level (i.e year of study) as the bases for stratification. The Technology-based Teaching Strategies Questionnaire (TTSQ) was developed by the researchers, who are also experts in test, measurement and research.

The instrument was divided into 2 sections. While section A seeks responses relating to students' demographic data, section B comprising of 20 items seeks responses relating to the use or exposure of students to technology-based teaching strategies by lecturers.

It was designed after the 4-point Likert Scale of Strongly Agree (SA), Agreed (A), Disagree (D) and Strongly Disagree (SD).

The instrument was accordingly validated and the reliability index of 0.72 was obtained using the Cronbach Alpha Estimate. The instrument was administered by trained research assistants completed and returned. Out of the six hundred and twenty four (624) questionnaires administered, only six hundred and eight (608) were correctly filled and returned giving a return rate of $96 \%$. For the statistical analysis, the one sample mean t-test and one-way analysis of balance were used to test the 3 hypotheses.

\section{Analysis of data and results}

Hypothesis of hypothesis analysis and presentation is done here.

Hypothesis 1: Students' exposure to technology-based teaching strategies is not significantly high.

For the exposure to technology-based teaching strategies to be considered significantly high, the researchers reasoned that the score representing such level of exposure should be greater than 50 (which is the mid point between Agreed and Disagreed, 2.5 multiplied by the 20 items measuring the dependent variable).

Thus, the statistical version of hypothesis 1 was that the mean score representing the level of exposure is not significantly greater than 50.00 .

$\mathrm{Ho}: \mathrm{u}=50.00$

$\mathrm{H} 1: \mathrm{u}>50.00$

A test of one sample mean (population $-t$ ) was used to test this hypothesis. The results of the analysis are as shown in Table 1.

Table 1:A Population t-test Analysis of whether Lecturers' use of technology-based teaching strategies is not significantly high.

\begin{tabular}{c|c|c|c}
\hline Variable & $\bar{X}$ & SD & $t$ \\
Use of technology-based teaching strategies. & 35.00 & & \\
Hypothesized Mean & 50 & 2.45 & 0.25 \\
\hline NSP $<.05$ (critical t-value $=1.96) \mathrm{N}=600$
\end{tabular}

The result shows that the calculated value of 0.25 is less than the critical t-value of 1.96 . Thus, the null hypothesis was accepted, meaning that the CRUTECH students sampled for this study are certain that their exposure to technologybased teaching strategies is not significantly high.

More so, considering the highest possible mean value of 50.00 , the mean value of 35.00 translates into $70 \%$. In other words, $70 \%$ of CRUTECH students sampled agreed that their lecturers do not use technology-based teaching strategies in their instructional delivery.

Hypothesis 2: Year of study does not significantly influence students' exposure to technology-based teaching strategies.

The statistical version of hypothesis 2 was that there is no difference in the mean scores of students from the various levels. Mathematically; Ho2: $u_{1}=u_{2}=u_{3}=u_{4}$. The one-way analysis of variance was used to test this hypothesis. The results of the analysis are as shown in Table 2. 
Table 2: One-way Analysis of variance of the effect of students year of study on their Lecturers' use of technology-based teaching strategies.

\begin{tabular}{ccccc}
\hline Variable & Group & N & $\bar{x}$ & SD \\
\hline Year of study & 1(year I) & 146 & 35.01 & 2.57 \\
& 2(year II) & 154 & 34.00 & 2.05 \\
& 3(year III) & 160 & 34.05 & 3.18 \\
& $4($ year IV) & 140 & 34.20 & 2.20 \\
\hline Source of Variation & SS & df & MS & F-ratio sig \\
\hline Between Groups & 72.05 & 3 & 24.02 & $0.84 \quad .231$ \\
Within Groups & 16970.26 & 596 & 28.47 & 0.84 \\
\hline Total & SS & df & &
\end{tabular}

NS at .05 level $\left(\right.$ critical $\left._{3,596}=1.96\right) \mathrm{N}=600$

The result shows that the calculated t-value of 0.84 is less than the critical t-value of 1.96. The null hypothesis is therefore accepted. This means irrespective of CRUTECH students year of study, their lecturers do not use or expose them to technology-based teaching strategies. It is also evident from table 2 (upper part) that the mean values representing the students' perception of the use of technology-based teaching strategies are about the same for all levels.

Hypothesis 3: Academic discipline does not significantly influence lecturers' use of technology-based teaching strategies. The statistical form of this hypothesis is that the means scores representing the use of technology-based teaching strategies as perceived by students from the following faculties; education, engineering, environmental sciences and communication technology are not significantly different. $\left(\mathrm{H}_{2}\right.$ : $\left.u_{1}=u_{2}=u_{3}=u_{4}=u_{5}\right)$. The one-way analysis of variance was employed in taking this hypothesis. The results of the analysis are as shown in Table 3.

Table 3: Results of one-way, ANOVA of effect of students' academic discipline on their perceived exposure to technology-based teaching strategies by their lecturers.

\begin{tabular}{clccc}
\hline Variable & Group & $\mathbf{N}$ & $\overline{\mathbf{X}}$ & SD \\
\hline Year of study & 1(Education) & 150 & 36.05 & 3.12 \\
& 2(Sciences) & 100 & 37.00 & 3.00 \\
& 3(Engineering) & 100 & 36.02 & 3.32 \\
& 4(Environmental Sciences) & 100 & 36.00 & 3.11 \\
& 5(Communication Tech) & 150 & 36.55 & 3.22 \\
\hline Source of Variation & SS & df & MS & F-ratio sig \\
\hline Between Groups & 82.18 & 4 & 20.55 & 0.69 .421 \\
Within Groups & 17684.66 & 595 & 29.72 & \\
\hline Total & SS & df & & \\
\hline
\end{tabular}

The result shows that the calculated t-value of 0.69 is less than the critical t-value of 1.96 at .05 level of significance and 595 degrees of freedom, thus, the null hypothesis is accepted. This means that academic discipline of students sampled do not affect their lectures' use of technology-based teaching strategies. More so, it is evident from Table 3 (upper part) that the mean scores was about the same for all the academic disciplines.

\section{Discussion of findings}

The major finding of this study is that Nigerian Academic Staff use of technology-based teaching strategies, as perceived by their students is not significantly high.

Thus, the result is not surprising, as apart from the lack of ICT equipment, most academic staffs are not computer literate. This finding is counter productive as it negates the benefits of TTS as reported by Stewart, et al 1992 and Lesgold, et al 1992. 
The next finding of this study is that students whether in their first, second, third or fourth year agreed that their lecturers were not using technology-based teaching strategies in their instructional delivery. The same was observed for various academic disciplines. The situation is unacceptable as Nigerian graduates cannot afford to be left behind in the use of this educationally acknowledged wonder of imparting knowledge in the $21^{\text {st }}$ century.

\section{Conclusion and recommendations}

From the findings, it can be concluded that Nigerian Academics are quite behind in this technological race as far as the classroom is concerned. It is therefore recommended that administrators of Nigerian Universities should be courageous enough to create technology-friendly classrooms that will enhance the use of web-base instruction, audiovisuals, computer-assisted, multi-media and virtual reality, in order for our Nation to reap the benefits of technology-based teaching as it is the case in the advanced countries. These researchers believe this scenario will bequeath on our graduates the necessary life-long skills expected of them.

\section{References}

Anderson, B. S., \& Speck, B. W. (2001).Using the technology in K-8 literacy classrooms. NJ: Prentice Hall.

Elliot, S. N., Kratochwill, T. R., Cook, J. L., \& Travers, J. F. (2000). Educational psychology: Effective teaching, effective learning. New York: McGraw Hill.

Kumar, P., \& Kumar, A. (2003).Effect of a web-based project on pre-service and in-service teachers' attitude toward computers and their technology skills. Journal of Computing in Teacher Education 19, 87-91.

Lesgold, A., Lojoie, S. P., Bunzo, M., \& Eggan, G. (1992).A coasted practice environment for an electronic troubleshooting job. In J. Larkin \& R. Chabay (eds.). Computer assisted instruction and intelligent tutoring systems: Shared goals and complementary approaches. NJ: Exlbaum.

Makti, N. A. (2000).Computer technology in Malaysia: teachers' background characteristics, attitudes and concerns. Electronic Journal of Information Science in Developing Countries. 3, 1-13.

Sadik, A. (2006). Factors influencing teachers' attitudes toward personal use and school use of computers: New evidence from a developing nation. Evaluation Review 30, 86-113.

Stewart, J., Hafner, R. Johnson, S., \& Finkel, E. (1992). Science as model building: Computers and high-school practice. Educational Psychologists. 27(3), $317-336$.

Tayo, B., Ajibade, A., and Ojedokun, O. (2009). Use of Computer and its relevance to teaching and learning in Nigerian educational system. Educational Research and Review. 4(10) Pp. 443-447. 
